\title{
Iconoclastia na filosofia alemã
}

OXENFORD, John. Iconoclasm in German Philosophy, in The Westminster Review, Vol. III, No. 2, Janeiro. 1, 1853, pp. 388-407.

Thiago de Souza Salvio ${ }^{\mathrm{I}}$

1. Parerga und Paralipomena [Parerga e Paralipomena: escritos filosóficos menores]. Por A. Schopenhauer. Berlin. 1851.

2. Die Welt als Wille und Vorstellung [O mundo como vontade e representação]. Pelo mesmo. Leipzig. 1819. Segunda edição. 1844.

3. Über die vierfache Würzel des Satzes vom zureichendem Grunde [Sobre a quádrupla raiz do princípio de razão suficiente]. Pelo mesmo. Rudolstadt. 1813.

4. Vom Willen in der Natur [Sobre a vontade na natureza]. Pelo mesmo. Frankfurt. 1833.

5. Die beiden Grundprobleme der Ethik [Os dois problemas fundamentais da ética]. Pelo mesmo. Frankfurt. 1841

6. Zeitschrift fur Philosophie [Gazeta de filosofia]. Por J. H. Fichte, Ulrici e Wirth. Halls. 1852. ${ }^{1}$

Poucos, de fato, nos aventuramos a afirmar, serão aqueles nossos leitores ingleses que estarão familiarizados com o nome de Arthur Schopenhauer. Menos ainda haverá quem sabe de que o ser misterioso ao qual esse nome pertence está trabalhando em algo há quarenta anos para subverter aquele inteiro sistema da filosofia alemã o qual tem sido erigido pelos professores universitários desde o falecimento de Immanuel Kant, e que, depois de seu longevo labor, ele acaba de ter sucesso em fazer a si mesmo ouvido maravilhosamente ilustrando aquela doutrina em acústicos o que mostra quão longo um intervalo deve decorrer entre quem está ciente que Arthur Schopenhauer é um dos mais engenhosos e autores legíveis do mundo, habilidoso na arte da formação de teoria, universal em realizações, inexaurível no poder de ilustração, terrivelmente lógico e

\footnotetext{
1 Referências do próprio autor no texto original; as notas da presente tradução acompanham convencionalmente as siglas: “N. A" para nota do autor, e "N. T" para nota do tradutor.
}

\footnotetext{
${ }^{\text {I }}$ Mestrando em Filosofia pela Universidade Estadual Paulista. thiagosouzasalvio@gmail.com. O presente trabalho foi realizado com apoio da Coordenação de Aperfeiçoamento de Pessoal de Nível Superior - Brasil (CAPES) - Código de Financiamento 001.
} 
inflexível na perseguição das consequências, e - a mais divertida qualificação para todos exceto às pessoas "atingidas" - um formidável golpeador de adversários.

A lista de trabalhos encabeçada neste artigo vai mostrar o quanto a mais excêntrico dos filósofos tem trabalhado, e quão contínuo suas obras têm sido. Em 1813 ele propôs uma nova teoria de causa e efeito; e o mundo filosófico da Alemanha disse - nada. Seis anos depois veio à tona a grande obra 'O mundo como vontade e representação', no qual toda uma teoria metafísica foi desenvolvida com a força e a clareza que a Alemanha não havia visto desde os dias de Kant, porém ainda a mesma palavra (com a exceção solitária) disseram - nada. Maravilhamo-nos não pelo temperamento de Schopenhauer, o qual, opinamos, de certos tratados polêmicos, não é dos mais amenos, era um pouco irritado. Por toda a Alemanha onde professores estavam espalhados recebendo seus aconchegantes salários, e sem uma faísca de gênio em sua composição, vendendo as palavras de algum mestre da arte filosófica, e elogiando um ao outro, como cada trazia afora sua trivial modificação de um sistema que havia sido ligeiramente cambiado de alguma prévia mudança, e ainda não poderia Schopenhauer receber uma palavra notória-não tanto quanto um pouco de abuso. Havia histórias de filosofia, compêndios de filosofia, e jornais filosóficos, mas nenhum poderia se encontrar difundindo o conhecimento das emanações de Schopenhauer. Afinal uma chance presencia a si mesma - quem pode dizer de qual parte o bom vento irá soprar? - a Real Sociedade Norueguesa de Ciências oferece um prêmio de melhor tratado sobre a liberdade da vontade, e no ano 1829 é ganho por Schopenhauer. Certamente a Alemanha, com sua conhecida predileção pelo ranque, reconhecerá a adjudicação de uma coroa de honra por uma sociedade real - uma sociedade científica, também, apesar de Drontheim não ser universalmente considerada como a moderna Atenas. Mas não, mesmo isso não poderia fazê-lo. O profeta foi grandioso apenas fora de seu país. Em vão ele demonstrou que, no sentido ordinário da palavra, liberdade da vontade era só uma quimera, estourada anos atrás, e em vão a Escandinávia aplaudiu, a Alemanha profissional ignorou a existência de Schopenhauer, seu panfleto, a Real Sociedade Científica, e a Noruega em si mesma, e passaram a ensinar "liberdade absoluta", e pregar "imperativos categóricos", assim como se o enérgico Schopenhauer nunca tivesse trazido o papel e caneta ao contato visível. Ainda Schopenhauer trabalha, não por bom ou mal relato, mas pelo que era mais desanimador, não relatar de todo. Sua última publicação, Parerga e Paralipomena, uma coleção de papéis filosóficos ilustrando seu próprio sistema, mas perfeitamente legível sem conhecimento prévio dele, é ainda mais vigoroso, e dá mais sinais de pensamento independente que a obra de sua juventude, que avistou a luz quarenta anos atrás. E finalmente encontramos que o filósofo negligenciado é conhecido, e, até certo ponto, apreciado. A história da filosofia alemã publicada pelo Professor Fortlage em 1852 - um livro altamente respeitável de seu gênero devota um não muito curto capítulo para o exame de Schopenhauer, como um dos 
fenômenos extraordinários do dia presente, e apesar do professor diferir do não-professor, a diferença é cortês. Dois artigos no último número da gazeta filosófica de J. H. Fichte mostra mais claramente esse Schopenhauer, se não agradável, é, a qualquer custo, considerado formidável.

Mas se há realmente algo extraordinário sobre Schopenhauer, porque quarenta anos de obscuridade? Essa é a questão, acima todas as outras, que o próprio Schopenhauer está preparado para responder. Porque, ele lhe dirá, que não é professor de filosofia, e nem um filósofo por comércio, não tem cadeira acadêmica, e tem sido entendido entre todos os filósofos universitários e tem havido um entendimento entre todos os filósofos universitários para derrubar qualquer homem que não seja um de seus oficiais. Os hegelianos podem divergir dos herbartianos, e os herbartianos dos hegelianos, e ambos dos schellingistas, e todos dos schleiermachianos, e os pequenos ramos que nascem das enormes árvores devem atropelar contra cada; mas tudo isso é feito civilizadamente, os adversários cumprimentam um ao outro no aprendizado, ou profundidade, ou na agudeza, ou compreensibilidade, contudo eles divergem das teorias propostas. Na outra mão, aflição ao desafortunado estudante de filosofia quem, havendo devotado ele mesmo a sabedoria do mundo oriental, a dialética dos gregos, a acuidade da França, ao duro, senso comum da Inglaterra, e, sobretudo, a suas próprias reflexões, deve ousar vir adiante com o resultado de seus labores, a menos que ele tenha assegurado uma licença para especular. Até onde a promulgação de suas visões é concernida, ele deve ser destinado ao solitário confinamento, e toda operação pela qual a opinião dele poderia encontrar seu caminho para o público deve ser eficazmente parada.

É claro que o clamor de Schopenhauer, que a filosofia alemã como ensinada pelos sucessores de Kant, não é fundada em qualquer investigação honesta da verdade, mas é um mero comércio, pelo qual o professor espera garantir a vida de sua esposa e família. pode ser interpretado como não mais do que outra forma da declaração da antiga raposa de que as "uvas são azedas". Schopenhauer, não recebendo nenhum incentivo dos magnatas reconhecidos da filosofia, salpica todo o sistema ao qual eles devem sua autoridade. Essa vexação e desapontamento tiveram alguma participação na produção da virulência com a qual ele ataca os filósofos em altos escalões é bastante provável, mas, ao mesmo tempo, não é de modo algum certo que uma palavra falada em raiva seja totalmente inapropriada; e, infelizmente, muitas obras filosóficas da Alemanha moderna encorajam a suspeita de que as animadversões de Schopenhauer não são totalmente infundadas.

Deixe qualquer inglês imparcial, que tenha passado por um ordinário curso de lógica, que tenha estudado matemática a um grau suficiente para fazê-lo entender os métodos de demonstração-que tenha lido os metafísicos de seu país, e vamos até acrescentar, as principais obras de Immanuel Kant-deixe este inglês, digamos, tomar qualquer uma das então chamadas obras científicas de Hegel, e honestamente pergunta ele mesmo, se esse é o estilo no qual um trabalho destinado a transmitir instruções deve 
ser escrito. A tendência geral do sistema, com seu otimismo, seu liberalismo, sua compreensão aparentemente agarrada, pode agradá-lo; as realizações universais do autor podem comandar sua admiração; mas, afora essas considerações, ele ainda se pergunte, se o sistema é realmente um sistema - se os raciocínios são raciocínios - se os elos que parecem conectar proposição à proposição realmente fazem qualquer coisa desse tipo. Se ele não for de temperamento presunçoso, será por um tempo modesto e imaginará que a medida da profundidade do autor excede a do seu próprio poder de penetração; mas se ele reflete que tem sido tolerávelmente capaz de seguir a cadeia de raciocínio em toda ciência existente, mas apenas essa ciência da metafísica alemã, como proposta pelas escolas de Schelling e Hegel, e que o processo empregado na matemática mais alta afinal de contas, não difere muito daquilo que é usado em conversas ordinárias; a modéstia enfim ficará um pouco fraca; e o aluno começará a suspeitar que ele olhou para o seu preceptor com algo além da devida medida de veneração. Que ele prossiga em seguida para pegar um desses compêndios da filosofia hegeliana, por meio dos quais algum discípulo do grande mestre oferece para tornar a fonte da sabedoria mais acessível aos não iniciados; ele vai agora achar que as coisas cresceram pior. O próprio Hegel, independentemente de seu sistema, tinha uma certa quantidade de informação ilustrativa e observação, que era muito mais valiosa do que a coisa ilustrada - assim como nos livros ilustrados, as imagens geralmente são muito superiores à imprensa - e estas eram acrescentado como uma espécie de comentário perpétuo ao esqueleto seco do sistema. Mas quando o assistente hegeliano se torna o preceptor, ele só pode dar a doutrina do mestre de uma forma mais curta e, conseqüentemente, mais seca, enquanto ele prova a natureza infrutífera da própria filosofia mostrando que ele dificilmente pode pronunciar uma palavra em uma ordem diferente daquela em que é colocado no livro original. As teorias de Platão, de Locke, de Kant, não precisam ser descritas de acordo com um determinado esboço fixo, totalmente destrutivo de todas as peculiaridades individuais, mas o intérprete pode infinitamente variar seu modo de exposição, e dar o jogo completo a qualquer poder descritivo com o qual ele pode ser abençoado. Não é assim com a filosofia de Hegel; seu sistema, se é realmente para ser ensinado, como qualquer outra ciência, requer uma reescrita completa: mas seus discípulos, longe de fazer algo do tipo, apenas repetem suas palavras, sem uma sílaba de elucidação. Qualquer coisa mais lucrativa do que as obras de segunda categoria pertencentes às várias escolas da filosofia alemã não pode ser encontrada em todo compasso da literatura. Tendo tomado uma dose suficiente dessa sabedoria filtrada, deixe que nosso pretenso inglês imparcial, que passou agora pela mais sonhadora série de argumentos pouco convincentes que a imaginação pode alcançar, busque agora conhecer o obstáculo que torna impossível toda união entre seu próprio raciocínio e o raciocínio nos livros antes dele. Ele é desajeitadamente contado pela escola que não é dotado de um "espírito especulativo"; ou se ele preferiu a região de Schelling à de Hegel, que ele não 
possui uma certa forma sobrenatural de intuição, que deve ser assumida como indispensável ao estudo filosófico.

Nesse ponto, a menos que sua autodepreciação seja do tipo mais anormal, ele ficará de fato um pouco desconcertado. As faculdades que o levaram até agora através dos mais diversos ramos de aprendizado e ciência, falham agora; e ele encontra uma espécie de raciocínio proposto a ele que ele não poderia usar para qualquer propósito de sua vida não, o que ele não poderia sequer descrever sem falar, como um papagaio, de um de seus livros. Neste momento, quando a fé está vacilando, deixe-o pegar uma página forte de Arthur Schopenhauer, e eis! uma suspeita desconfortável, que há algum tempo está flutuando em sua mente, começará a assumir uma forma tangível. Não será como se Schopenhauer, em suas invectivas contra Hegel e Schelling, lhe ensinasse alguma coisa nova, mas como se uma repentina convicção fosse despertada em seu próprio peito. Não estamos preparados para percorrer toda a extensão de Schopenhauer dizendo que todo o ensino dos professores modernos é uma mera questão de salário; mas estamos certos de que as partes que ele ataca trabalharam ao máximo de seu poder para apoiá-lo em sua noção ${ }^{2}$.

Os filósofos polêmicos são frequentemente mais habilidosos na destruição do que na construção, exibindo um mundo de agudeza na escolha dos pontos fracos do edifício de um adversário, mas uma falta singular de cuidado e precisão em criar os seus próprios. Schopenhauer é o reverso de tudo isso. Longe de dissecar as teorias de Schelling e Hegel, ele lhes dá uma saraivada de abusos, como se não os considerasse dignos das dores de um argumento; e então ele pacientemente constrói seu próprio sistema, apoiando-o à medida que ele prossegue com argumentos perfeitamente inteligíveis; sua real refutação de todos os outros sistemas consistindo na confiança com a qual ele aponta para os seus. Apelando ao senso comum de seus leitores, para induzi-los a deixar de ouvir um número de palavras estranhas de significação mais vaga, ele reduz vários termos ao significado que eles traziam antes do tempo de Kant; e ele propõe uma teoria com a qual eles podem concordar ou não, mas que dificilmente podem falhar em entender. A falha geral dos metafísicos alemães é que eles nem sequer oferecem uma boa base de ataque. Os sistemas são tão estranhamente fundamentados, e as palavras são tão incertas em sua importância que você não sabe quando está lutando com sombras ou quando está com a substância. Atingido de admiração por um tipo estranho de engenho, ou repugnado por uma crescente obscuridade, você não se arrisca em nenhuma das disputas, mas simplesmente não fica convencido. Agora Schopenhauer oferece um sistema compreensível, claramente redigido; e você pode saber, além da possibilidade de uma dúvida, o que você está aceitando e o que está rejeitando. Nunca um autor tentou se impor menos ao seu leitor.

${ }^{2}$ Vide artigo "Literatura contemporânea na Alemanha", in Westminster Review de Abril, 1852 [N. A]. 
Vamos, no entanto, nos apressar em remover uma impressão falsa que provavelmente fizemos. Pode-se imaginar que estamos condenando totalmente os supostos sucessores de Kant e exaltando Schopenhauer e, portanto, gostaríamos que fosse rapidamente compreendido, que tudo o que dissemos se aplica não à doutrina ensinada, mas à maneira de ensinar. As tendências dos modernos filósofos alemães, embora possam diferir entre si, são liberais e enobrecedoras no mais alto grau; e sejam eles - como acreditam seus discípulos entusiastas - genros exaltados, inspirados pelo amor da verdade, ou meros membros de um ofício lucrativo, eles ainda são órgãos importantes para a difusão de idéias elevadas, que às vezes tomam a forma de um elevado sistema de moralidade, algumas vezes, tem por objetivo a fundação de um esquema abrangente de ciência. Seu grito de guerra, por mais estranha que seja a linguagem em que se possa expressar, ainda é "progresso!" e, portanto, ainda são os simpatizantes pedantes do espírito da civilização moderna. Não é em suas doutrinas, em sua tendência última, que o pensador inglês imparcial encontra tanto a objetar, como no erro constante (a seus olhos) de abstrações por existências reais, de não-raciocínios para raciocínios, de palavras para coisas. Que muitos dos mais novos filósofos alemães, embora criados nas escolas de vinte anos atrás, chegaram a uma convicção de que nem tudo está certo neste particular, é suficientemente demonstrado pelas produções daqueles autores, que agora se agrupam em torno do Fichte mais jovem, e mostrar uma reverência condigna para o que podemos chamar de um modo sensato de pensar. Que qualquer um compare os últimos números do Zeitschrift für Philosophie [Gazeta de Filosofia], editado por J. H. Fichte, com o antigo Jahrbücher der wissenschaftlichen Kritik [Anais de crítica científica], - esse órgão da escola hegeliana, em que um romance ordinário não pode ser revisto sem o emprego de um arsenal inteiro de armas técnicas, e ele ficará impressionado com a melhoria que ocorreu.

Por outro lado, enquanto o ensinamento de Schopenhauer é o mais genial, o mais engenhoso, e - acrescentamos, o mais divertido que pode ser imaginado, a doutrina ensinada é a mais desalentadora, a mais repulsiva, a mais oposta às aspirações de o mundo atual, que o mais ardente dos confortos de Jó poderia inventar. Tudo o que a mente liberal aguarda com esperança, se não com confiança - a extensão dos direitos políticos, a disseminação da educação, a irmandade das nações, a descoberta de novos meios de subjugar a natureza teimosa - deve ser abandonado como um sonho vão, se alguma vez a doutrina de Schopenhauer for aceita. Em uma palavra, ele é um "pessimista" declarado; é o seu grande resultado, que este é o pior de todos os mundos possíveis; não, tão absolutamente insusceptível de melhora, que a melhor coisa que podemos fazer é nos livrarmos completamente, por um processo que ele claramente estabelece.

No começo de sua teoria, Schopenhauer aparece como um compositor de Kant com Berkeley; e aqui podemos observar que, embora ele acabe se revelando um místico, no sentido de St. Antony da palavra, ele primeiro se apresenta como um admirador especial do 
senso comum dos ingleses. Hobbes, Berkeley e Priestley, cuja existência quase foi ignorada pelos modernos professores alemães, estão ao alcance de seus dedos, e ele os cita não apenas como almas afins, mas como autoridades. Tudo o que ele diz, enquanto expõe as ilusões do mundo visível, e nega a liberdade da vontade (em que último processo ele é muito grato a Priestley) parece tão justo e acima de tudo, que o leitor desavisado não tem suspeita de o terrível resultado que está à mão. Berkeley foi mais longe do que Kant (que sem sucesso esforçou-se refutá-lo) ao negar a realidade do mundo ao seu redor, enquanto Kant constituía um sistema a priori, situado na mente mesma, do qual Berkeley não tinha noção. Nada poderia ser mais fácil do que reconciliar os dois sistemas, e Fichte já havia dado o exemplo de negar a realidade daquela misteriosa Ding-an-sich [coisa em si], que Kant colocou por trás de seus fenômenos.

Como este artigo é destinado principalmente àqueles que estão em algum grau familiarizados com a filosofia alemã, podemos supor que nossos leitores estão tão familiarizados com a teoria de Kant, quanto estão cientes de que ele considerava o tempo e o espaço como meras formas da mente, a qual recebe as impressões das coisas externas, mas que não existiam nas coisas em si; e que, além disso, ele supunha que determinadas leis gerais, como por exemplo, a de causa e efeito, também tivessem assento na mente, de modo que, sob essas leis, todos os julgamentos deveriam ser formados. O espaço, o tempo e as "categorias" - os meios pelos quais os objetos sensíveis são revelados, e as leis sob as quais eles são objetos de pensamento e de sentido, são, portanto, a priori, da mesma maneira - para usar um símile comum - como se disséssemos que um tom verde espalhado sobre a face da natureza viria, a priori, para um homem destinado a usar óculos verdes para a vida. Aqui surge a dificuldade fundamental, que impede os pensadores da escola inglesa de aceitar o ensinamento do alemão. Com Kant, no entanto, a diferença do inglês é menos importante do que com seus sucessores. Eles realmente se esforçam para estabelecer teorias que levem os homens muito além dos limites da natureza, mas sua teoria das formas a priori tem uma tendência de restrição, não uma tendência de extensão. As "categorias" assentadas na mente são meramente de valor, na suposição de que objetos são apresentados sobre os quais elas podem ser empregadas, e não temos o direito de empregálas quando o mundo dos sentidos deixar de existir. Para retornar ao símile, o homem com os óculos verdes não deve imaginar que, porque a natureza iluminada usa um tom verde, a escuridão também aparecerá verde. Segundo o kantismo consistente, a teologia física, com seus sumos sacerdotes Durham e Paley, e sua parafernália de Tratados Bridgewater, é apenas um absurdo amistoso, baseado em uma extensão ilegítima da lei de causa e efeito a um objeto que está além de sua jurisdição. Teoricamente falando, o homem, de acordo com Kant, não tem o direito de afirmar ou negar a existência de um Deus, de uma alma imaterial ou, de fato, de qualquer entidade, que esteja além da observação dos sentidos. Teoricamente, o kantismo é ateísmo negativo, embora por sua "razão prática" Kant readmita na porta dos fundos as idéias que foram ignominiosamente lançadas do pórtico. 
A parte teórica do sistema de Kant é, com algumas modificações, adotada por Schopenhauer; isto é, ele aceita a idealidade do tempo e do espaço, mas reduz as doze categorias, que Kant deduziu das formas de proposições estabelecidas na lógica comum das escolas, à simples lei de causa e efeito, que, no entanto, aparece em várias formas. Agora, é aquela corrente infinita pela qual todos os fenômenos do mundo visível estão conectados (a lei de causa e efeito, apropriadamente assim chamados), agora é a conexão que existe entre as premissas e a conclusão de um argumento. Mas, qualquer que seja a forma, é a lei pela qual a mente é compelida a pensar, quando contempla os objetos do mundo externo.

A faculdade que atua sob essa lei de causa e efeito é chamada por Schopenhauer de entendimento, e ele atribui a sua operação muito do que até agora foi referido (por Kant entre outros) apenas aos sentidos. E podemos observar aqui Schopenhauer em geral, que, diferentemente de muitos de seus conterrâneos, que se deliciam em tropeçar na abstração e encolher, por assim dizer, por instinto, a partir de ilustração familiar, ele sempre exibe uma indústria mais louvável na coleta de fatos, que podem servir para expor seus pontos de vista sob uma nova luz. Registros zoológicos, transações de sociedades eruditas, poetas clássicos de várias línguas, até anedotas de jornais, são todos saqueados com zelo, e os tesouros que eles oferecem são usados com discriminação. É para a agudeza com que ele se lança numa ilustração feliz, que Schopenhauer é justamente grato pelo charme peculiar de seus escritos.

O entendimento (Verstand), segundo Schopenhauer, que é o inverso de um cartesiano a esse respeito, é possuído pelo homem, em comum com outros animais, embora varie em graus de intensidade. Não tem poder de generalização; mas suas funções estão confinadas a objetos únicos e imediatos, e aquele que sabe que costeletas-de-carneiro causará uma cessação da fome, está apenas na mesma situação que um cavalo, que praticamente afirma a mesma coisa de um monte de feno. Habilidade prática, engenhosidade, em suma, a maioria das facilidades para "entrar no mundo" depende, em grande parte, da agudeza do entendimento, da atribuição de cada efeito à sua causa apropriada e da tendência habitual de se errar nesse particular, constituem estupidez ordinária.

Na definição da razão (Vernunft), Schopenhauer difere grandemente de todos os seus contemporâneos. Com eles, a razão é uma faculdade compreensiva, que, desprezando o finito, se mostra agarrando, ou contemplando, ou suspeitando o infinito, o absoluto ou o incondicionado (de acordo com o vocabulário particular que o filósofo adota), mas que está sujeito à inconveniência especial, que muitos pensadores sem preconceitos estarão inclinados a suspeitar que não existe de todo. O que se entende por compreensão é sempre suficientemente inteligível, mas quando um filósofo alemão comum começa a falar sobre a razão, seu discurso geralmente se eleva ao sublime nebuloso. A advertência de Kant, que 
viu os vôos ambiciosos da razão nas regiões da ciência, que não deveria ser recebido como um instrutor teórico, foi pouco atendida, e da razão foi feita chocar qualquer monstruosidade que a cabeça filosófica pode fantasiar. Com Schopenhauer a razão toma uma posição ainda mais humilde que a de Kant, que, colocando-o à frente de seu sistema moral, e dando-lhe uma alta exaltação prática, abriu o caminho para aquela estranha apoteose de formas abstratas, que encontramos em seus sucessores tardios, embora ele mesmo tivesse protestado contra isso. O que Schopenhauer diz sobre esse assunto pode servir como um exemplo de seu estilo desapaixonado:

“Além dessa classe de percepções, que já consideramos, ou seja, aquelas que podem ser reduzidas a espaço, tempo e matéria, se considerarmos o objeto, ou a pura sensibilidade e compreensão, se considerarmos o assunto, é só no homem, entre todos os habitantes da terra, outra faculdade de conhecimento, outro modo de consciência, que, com precisão antecipada, tem sido chamado de reflexão. Pois é, de fato, um reflexo, algo deduzido daquele conhecimento intuitivo, mas, no entanto, tem uma natureza totalmente diferente da do resto, e nada conhece de suas formas, enquanto, com respeito a ela, a lei de causa e efeito, que prevalece sobre todos os objetos, aqui usa um aspecto perfeitamente diferente. Essa nova consciência - essa consciência elevada a um poder superior - esse reflexo distinto de tudo intuitivo nas concepções não-intuitivas da razão, é somente isso que dota o homem dessa circunspecção, que distingue tão completamente sua própria consciência da dos animais, e que faz com que toda a sua carreira terrena seja tão diferente da de seus irmãos irracionais. Ele é igualmente superior em dor e sofrimento. Eles vivem apenas no presente; ele, ao mesmo tempo, no futuro e no passado. Eles satisfazem seus desejos imediatos; ele faz preparações artificiais para o futuro, ou melhor, para tempos que ele não viverá para ver. Eles estão expostos às impressões do momento, à operação de motivos imediatos; ele é determinado, por concepções abstratas, independente do presente. Ele, portanto, executa planos bem digeridos, ou age de acordo com máximas fixas, sem considerar as circunstâncias secundárias e as impressões casuais do momento. Ele pode assim, por exemplo, inventar calmamente meios artificiais para sua própria morte, pode tornar-se impenetrável por dissimulação, pode levar um segredo com ele para o túmulo e, por último, tem uma escolha real entre vários motivos.O animal bruto, em outra mão, é determinado por impressões presentes; $\mathrm{O}$ medo da punição imediata pode apenas refrear seus desejos, até que, por fim, o medo se torna um costume e, dessa forma, determina o animal, sob o nome de "treinamento" ou "arrombamento". O animal tem sentimento e intuição; o homem, além disso, pensa e sabe; a vontade é comum a ambos. O animal comunica seus sentimentos por sons e gestos, enquanto o homem comunica (ou oculta) seu pensamento pela fala. O discurso é o primeiro produto e a implementação necessária de sua razão. Assim, nas línguas grega e italiana, fala e

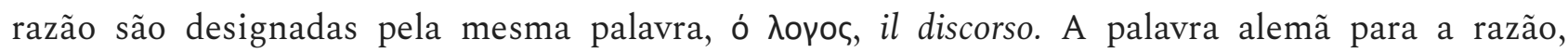
"Vernunft", vem do verbo "vernehmen", que não é sinônimo de "hören", para ouvir, mas significa uma percepção do pensamento transmitida pelas palavras. É somente pela ajuda da fala que a razão alcança seus resultados mais importantes, como a ação harmoniosa de vários indivíduos - a cooperação organizada de milhares - civilização - estados; novamente a ciência - a preservação das primeiras experiências - a combinação de objetos em uma concepção geral - a comunicação da verdade - a difusão do erro - o pensamento e a criação poética - dogmas religiosos e superstições. O 
animal não sabe nada da morte até que realmente venha a ele; o homem se aproxima conscientemente de sua morte a cada hora, e isso dá à própria vida um aspecto duvidoso aos olhos de alguém que não percebeu que a aniquilação constante é o caráter da vida por toda parte. É principalmente neste relato que o homem tem sistemas de filosofia e religião, embora se o que recomendamos acima de tudo em suas ações, ou seja, a retidão de conduta e nobreza de disposição é o resultado de qualquer um deles é incerto. Por outro lado, entre as produções que certamente lhes pertencem e, portanto, apenas a razão, podem ser mencionados os absurdos excêntricos dos filósofos de diferentes escolas e os costumes estranhos e às vezes cruéis dos sacerdotes de diferentes religiões". - Die Welt als Wille und Vorstellung [O mundo como vontade e representação] ${ }^{3}$.

A razão, apesar de criar a ampla distinção entre homem e animal, e apesar de originar tanto que é enobrecedora e degradante para a natureza humana, nada mais é, segundo Schopenhauer, que o poder de formar, o que Locke chama de "idéias abstratas"; e até agora o velho inglês e o moderno filósofo alemão concordam o máximo possível. Com todas as suas maravilhas, a razão ainda não pode fazer nada além de organizar as impressões já dadas pela intuição, e longe de ser uma fonte de novos conhecimentos, ela meramente pega em segunda mão o conhecimento já adquirido em outra forma. Como um meio de poder, a razão certamente eleva o homem acima do resto da criação animal; mas, como meio de conhecimento, a intuição é a mais segura das duas. Neste ponto da doutrina de Schopenhauer, uma teoria da matemática, que lembrará alguns leitores de Gassendi, é introduzida. Os geômetras, que seguiram na esteira de Euclides, são todos, pensa ele, tão equivocados, que negligenciaram o método mais seguro da intuição, que lhes ficava aberta, na construção de suas figuras, e baseavam o demonstrações de suas proposições sobre o raciocínio lógico, que é, na melhor das hipóteses, apenas um substituto. Kant estabeleceu a verdade, que o espaço é uma forma a priori da intuição e Schopenhauer o adotou, o último prossegue dando pistas de como um sistema de geometria pode ser inventado, no qual não

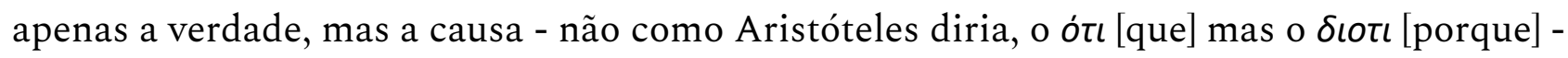
das proposições podem ser provadas. Não temos espaço suficiente para discorrer sobre esse mero episódio da teoria, mas apenas observamos que a demonstração da qual ele mais se baseia para um espécime é retirada do Menon de Platão.

Todo o mundo visível não é mais do que uma massa de irrealidade consistente. $O$ espaço, o tempo e a lei da causalidade são, todos eles, meras formas da mente, que nada têm a ver com a natureza real das coisas, mas apenas as concernem na medida em que se tornam objetos de um sujeito que percebe. Toda causa, por sua vez, é o efeito de outra causa, e quanto a um começo real de bonâ fide [boa fé] por que pedir algo do tipo quando o mundo inteiro é uma ilusão - o "véu dos maia", como os sábios indianos o chamam, e como Schopenhauer, cuja fé religiosa oscila entre o bramanismo e o budismo, gosta de chamá-lo

\footnotetext{
${ }^{3}$ Cf. Die Welt als Wille und Vorstellung, Erster Band. Dritte Auflage, 1859 (§ 8, I 44), O mundo como vontade e como representação, tomo I (2015, pp. 42-43) [N. T].
} 
depois deles. Quanto ao modo como aqueles que pensam o contrário são tratados por nosso sábio colérico, isso pode servir como um exemplo de sua maneira apaixonada:

"Agora, o que foi feito por nossos bons e honestos professores alemães de filosofia, que prezam a mente e a verdade acima de tudo - o que foi feito por eles, digo, por essa prova cosmológica muito querida amada, depois que Kant, em sua 'Crítica da Razão', havia causado um golpe mortal? Então bom conselho era um bem caro, pois (e isto os dignos sabem, embora não o digam) porque o causa prima, como causa sui é uma mera contradição em termos, embora a primeira expressão seja muito mais usada que a última, e é geralmente proferida com um ar muito sério e até solene. Não, muitas pessoas, reverendos ingleses em particular, viram seus olhos, da maneira mais edificante, quando, com ênfase e emoção, falam dessa contradição em termos - uma causa primeira. Eles sabem muito bem que uma causa primeira é tão inconcebível quanto um local, onde o espaço chega ao fim ou o momento em que o tempo teve um começo. Pois toda causa é uma mudança, com respeito à qual devemos necessariamente perguntar depois da mudança precedente, que a provocou, e assim por diante - in infinitum, - in infinitum! Não, nem mesmo um primeiro estado da matéria, do qual todos os outros procederiam, é concebível. Pois se esse estado em si fosse a causa, eles devem ter existido desde toda a eternidade, de modo que o estado presente não teria começado apenas agora. Se, por outro lado, começou a ser causal em um determinado momento, algo deve ter mudado naquele momento, de modo a terminar seu repouso. Neste caso, algum agente estrangeiro deve ter se aproximado, uma mudança deve ter ocorrido, depois da causa da qual (isto é, depois de uma mudança precedente) devemos imediatamente inquirir, e assim estamos novamente na escada das causas, e são chicoteados cada vez mais pelas leis inexoráveis da causalidade -in infinitum, - in infinitum. A lei da causalidade não é tão complacente a ponto de permitir-se ser tratada como um treinador de retaguarda, que podemos mandar para casa assim que tivermos completado nossa jornada. É como a vassoura viva de Zauberlehrling [aprendiz de feiticeiro], de Göthe, que, uma vez posta em atividade, nunca deixará de se mexer e de extrair mais água, de modo que apenas o velho conjurador poderá aquietá-la novamente. Mas oxalá! nossos cavalheiros não são conjuradores. O que eles fizeram então, estes nobres e íntegros amigos da verdade, que estão apenas esperando por mérito real para proclamar isso ao mundo, assim que ele se mostra, e quem, quando um indivíduo aparece, quem realmente é, o que pretendem ser, longe de desejar sufocar suas obras por um silêncio astuto ou ocultação tímida, torna-se, ao contrário, os arautos de sua fama, como certamente - tão certamente quanto a loucura ama a compreensão. O que agora esses cavalheiros fizeram com seu velho amigo, a demonstração cosmológica, agora tão dificilmente pressionada, e colocada de costas. Oh, eles imaginaram um dispositivo certo e astuto. "Amigo", disseram eles à manifestação cosmológica, "você está numa situação triste, uma triste situação, de fato, desde o seu infeliz encontro com aquele velho sujeito de cabeça dura de Königsberg - eis uma situação tão triste quanto seus dois irmãos, as demonstrações ontológicas e físico-teológicas. Não importa, não abandonaremos você - na verdade, você sabe que somos pagos para ajudá-lo -, mas não pode ser ajudado - você precisa mudar seu nome e se vestir, pois, se chamarmos você pelo seu próprio nome, todos correrão. longe. Em seu incógnito, vamos levá-lo para debaixo do braço e introduzi-lo na sociedade, apenas lembre - incógnito, deve ser. Seu objeto deve, doravante, levar o nome do "Absoluto" - que soa estranho, imponente e gentil. Somos bons juízes, até onde a gentileza vai com os alemães. Todo mundo sabe o que significa e se pensa a si 
mesmo sábio na barganha”. - Ueber die vierfache Wurzel des Satzes vom zureichendem Grund [Sobre a quádrupla raiz do princípio de razão suficiente]. ${ }^{4}$

O extrato acima é característico em mais de um aspecto. Isso mostra que uma estranha mistura de argumento de sarcasmo, invectivo e de senso comum, que constitui o estilo polêmico de Schopenhauer, e, ao mesmo tempo, permite que o ressentimento privado, que nunca é totalmente esquecido, apareça na forma de amarga ironia.

O mundo inteiro sendo assim disposto em uma teoria não materialmente diferente da de Kant, Schopenhauer chega ao seu próprio solo. Até agora ele trabalhou ostensivamente no ensino de outros, seus próprios acréscimos são bastante episódicos do que de outro modo; mas agora vem o lampejo da verdadeira originalidade.

Deve ser lembrado que depois de Kant ter explicado o mundo fenomenal, tornando o espaço e o tempo meras formas da percepção, e as categorias meras formas do entendimento, ele deixa um algo indefinível, ao qual ele dá o nome da "coisa em si" (Ding an sich), isto é, a coisa considerada separada por si mesma, independentemente de sua contemplação pela mente percebedora. Isso é suscetível apenas de uma definição negativa; está além das fronteiras do nosso conhecimento, e tudo o que podemos dizer é que não sabemos nem podemos saber nada sobre isso. Assim, no caso de uma rosa, sua extensão pertence à forma de intuição (espaço); seu arranjo, sob qualquer categoria concebível, mesmo a da unidade - de fato, sua existência como um objeto distinto, pertence ao entendimento; mas ainda há algo separado destes, que é representado pelas meras sensações, o cheiro peculiar e cor da rosa, e esta é a manifestação do "grande desconhecido". A admissão de que ainda existe um resíduo depois que o mundo dos sentidos foi explicado, constitui uma diferença marcante entre Kant e Berkeley: mas essa diferença foi removida por Fichte, que tendo pouco respeito pelo mistério inacessível deixado por seu antecessor, declarou "coisa em si mesma não é mais do que mera criação da mente”.

Essa doutrina de Fichte é especialmente impugnada por Schopenhauer. Tendo já estabelecido a posição, que a causalidade é uma mera lei para conectar fenômenos uns com os outros, ele mostra imediatamente a falácia de usar a emanação ou qualquer outra forma desta lei como um meio de explicar existências independentes. A mente não pode ser a causa da "coisa em si", porque nenhum destes sendo fenômenos, ambos estão além do alcance da jurisdição da causalidade.

O que, então, é a "coisa em si"? "A vontade", responde Schopenhauer, com um ar de evidente triunfo; "e esta resposta é a grande descoberta da minha vida." O mundo, como uma coleção de objetos invisíveis, é apenas uma série de fenômenos, de sonhos - ou melhor, de tais meros sonhos, que é difícil definir a diferença entre dormir e acordar; mas o mundo em si é uma enorme vontade, constantemente apressando-se para a vida. Quando

${ }^{4}$ Cf. Ueber die vierfache Wurzel des Satzes vom zureichendem Grund, Vierte Auflage, 1875; §20, pp. 38-39. 
estamos conscientes de objetos externos, apenas um lado deles é revelado a nós - a saber, o lado externo; enquanto que, quando nos tornamos nosso próprio objeto, estamos conscientes de nós mesmos não apenas como fenômenos, mas como vontade, o que não é fenômeno; e aqui temos a chave para todo o mistério, pois argumentando por analogia, podemos estender essa vontade, que em nós é acompanhada pela consciência, para o mundo inteiro, incluindo até mesmo suas partes inconscientes e inabitadas.

"Vamos agora fazer uso do conhecimento que temos da essência e operação de nossos próprios corpos, como uma chave para a essência de cada fenômeno na natureza, e com respeito àqueles objetos que não são nosso próprio corpo - e, portanto, não são revelados a nós de uma maneira dupla, mas apenas como representações exteriores - formam um julgamento de acordo com a analogia daquele corpo e essência, que, por um lado, são fenômenos, como ele próprio, por outro lado, quando deixamos de lado sua existência como fenômenos do sujeito, o que permanece deve, em sua essência, ser o mesmo que em nós mesmos chamamos de vontade. Para que outro tipo de existência, na realidade, devemos atribuir ao resto do mundo corpóreo? De onde adquirem os elementos de que tal mundo poderia ser composto? Além da vontade e dos fenômenos, nada nos é conhecido, nem mesmo concebível. Quando atribuímos ao mundo corpóreo, que só existe em nossa própria faculdade perceptiva, a maior realidade da qual estamos conscientes, atribuímos a ela aquela realidade que todos encontram em seu corpo, pois isso para nós é mais real do que qualquer outra coisa. Mas quando analisamos a realidade desse corpo e suas ações, descobrimos, além de sua existência como um dos nossos fenômenos, nada além da vontade; aqui é toda a sua realidade, e nunca podemos encontrar qualquer outro tipo de realidade, que podemos atribuir ao mundo corpóreo. Se, portanto, o mundo corpóreo é para ser algo mais que um mero fenômeno de nossas mentes, devemos dizer que, além desta existência visível ${ }^{5}$, é em si mesmo e em sua própria essência aquilo que imediatamente encontramos em nós mesmos como a vontade. Devemos, no entanto, distinguir da verdadeira essência da vontade aquilo que não pertence a ela, mas apenas a sua aparição no mundo dos fenômenos, dos quais existem muitos graus; como, por exemplo, seu acompanhamento pelo conhecimento e sua conseqüente determinação por motivos. Isso não pertence à sua essência, mas apenas às suas manifestações mais claras, na forma de animal e homem. Quando digo, portanto, que o poder que impulsiona a pedra em direção à terra é, em sua própria essência, à parte de toda manifestação, a vontade, não pretendo expressar o absurdo, que a pedra é consciente de um motivo de ação, porque a vontade aparece acompanhada de consciência no homem”. - Die Welt als Wille und Vorstellung [O mundo como vontade e representação].

Não obstante, a gravitação, a eletricidade e, de fato, toda forma de ação, desde a queda de uma maçã até a fundação de uma república, é uma expressão da vontade e nada mais. O mundo é essencialmente vontade e nada mais, desenvolvendo-se numa série de manifestações, que se elevam em escala graduada, das chamadas leis da matéria, para

\footnotetext{
${ }^{5}$ Fomos obrigados a fazer uso aqui e acolá, de expressões parafrásticas para evitar um intento de traduzir a intraduzível palavra "Vorstellung" [N. A].

${ }^{6}$ Cf. Die Welt als Wille und Vorstellung, Erster Band. Dritte Auflage, 1859 (§ 19, I 122), O mundo como vontade e como representação, tomo I (2015, pp. 125-126) [N. T].
} 
aquela consciência, que nos animais inferiores atinge o estado de sensibilidade e compreensão ( no sentido de Schopenhauer), e no homem chega a esse estado superior chamado razão. Nos estágios iniciais, suas manifestações têm um aspecto mais geral; uma pedra é senão numericamente distinta de outra da mesma espécie, mas a distinção aumenta à medida que sobem na escala, e quando atingem a forma do homem, cada indivíduo é perfeitamente distinto de todo o resto, e esse fenômeno, que chamamos de “caráter"”, é produzido.

No entanto, Schopenhauer não para de estabelecer uma enorme abstração, à qual ele dá o nome da vontade - e que nessa condição indefinida seria pouco mais que uma cifra pomposa, mas ele passa a marcar a linha de suas operações, e essa talvez seja a parte mais engenhosa de sua teoria. As antigas Ideias Platônicas ocorrem em sua mente, e elas não apenas respondem a seu propósito, mas a maneira como ele as usa lhe dá uma maior afinidade ao antigo filósofo da Grécia, do que é exibido por qualquer um de seus contemporâneos, embora o nome de Platão é muitas vezes suficiente em suas bocas. As Idéias de Platão, que alguns dos nossos metafísicos do século passado denominaram "Universais" - aquelas formas sobrenaturais das quais os objetos sensíveis participam, embora eles mesmos nunca sejam revelados aos olhos mortais em toda a sua pureza aquelas essências eternas, que nunca passam, embora os indivíduos através dos quais são imperfeitamente revelados, surgem e perecem em rápida sucessão - aquelas "ideias", que têm intrigado tantos filósofos, e causado tantos papéis a serem cobertos de controvérsias infrutíferas, são interpretadas por Schopenhauer como sendo os vários estágios nos quais a manifestação da vontade ocorre. Em toda ciência há algo assumido, que é usado para explicar ou classificar vários fenômenos, mas que não é explicado por sua vez, sendo considerado, no que diz respeito a essa ciência particular, inexplicável. Assim, na mecânica, a gravitação é assumida, mas não deduzida, e na história, uma vontade humana capaz de ser influenciada por motivos é um postulado necessário. Os vários fenômenos do mundo expressam certas leis e atributos essenciais que, sendo forçados a aparecer sob a forma de espaço, assumem uma individualidade que não pertence intrinsecamente à sua própria natureza. Em toda ciência há algo assumido, que é usado para explicar ou classificar vários fenômenos, mas que não é explicado por sua vez, sendo considerado, no que diz respeito a essa ciência particular, inexplicável. Assim, na mecânica, a gravitação é assumida, mas não deduzida, e na história, uma vontade humana capaz de ser influenciada por motivos é um postulado necessário. Os vários fenômenos do mundo expressam certas leis e atributos essenciais que, sendo forçados a aparecer sob a forma de espaço, assumem uma individualidade que não pertence intrinsecamente à sua própria natureza. A pedra individual pode passar, ou pode ser absorvida em outro estado de existência, mas impenetrabilidade e gravidade, que constituíam sua natureza essencial - suas "realidades reais", como Coleridge diria, permanecem imóveis, intocadas pelo naufrágio de 
incontáveis individualidades. As "Ideias" mantêm assim um lugar intermediário entre a vontade, como "Coisa em si", e os fenômenos, sendo os pontos nos quais a vontade entra na região fenomenal. Muitos de nossos leitores, que consideraram tudo o que até agora descrevemos como senso comum tolerável, provavelmente estarão inclinados a sorrir para essa parte da doutrina, como a visão de um sonhador alemão. Mas eles vão sorrir muito menos, se estiverem familiarizados com o tipo de atmosfera filosófica em que Schopenhauer foi forçado a se mudar, durante as dinastias de Schelling e Hegel. De qualquer forma, sabemos perfeitamente o que Schopenhauer quer dizer com suas idéias mas quem pode dizer tanto quanto a Ideia Absoluta de Hegel?

Não há conexão causal entre a vontade e suas manifestações, pois, como Schopenhauer já explicou, a causalidade não tem jurisdição além do mundo dos fenômenos; mas o corpo é a própria vontade em sua forma manifesta, e para explicar essa visão em um detalhe, que não temos espaço para seguir, todos os tipos de ajuda são emprestados da ciência fisiológica, os diferentes órgãos do corpo sendo explicados de acordo com essa hipótese, e o cérebro humano sendo o representante visível da razão humana. Uma teoria da arte muito engenhosa está igualmente conectada com essa interpretação das "ideias".

Neste estágio da teoria, a doutrina moral de Schopenhauer pode ser convenientemente introduzida. Virtude, que, em sua opinião, é melhor ensinada pelos sábios do Hindustão que pelos teólogos judeus ou cristãos, é baseada em um reconhecimento prático, que o mundo inteiro é apenas uma manifestação da mesma vontade como a nós mesmos-que os vários homens e os animais à nossa volta estão tão intimamente ligados a nós, por causa de sua substância comum, que dizer que eles são "parecidos" é apenas uma fraca expressão. "Tu mesmo és aquilo", é a máxima moral do mestre hindu, que aponta para o mundo circundante, ao declarar essa identidade - e a única virtude é a simpatia. Esta é também a doutrina moral do cristianismo, quando ordena a seu professor amar o próximo como a si mesmo, mas o cristianismo é tão menos perfeito que o hinduísmo, que não inclui, em seu comando do amor universal, a criação bruta. Daí a crueldade para com os animais - um vício que Schopenhauer defende com grande repugnância, freqüentemente elogiando os esforços da sociedade inglesa "Prevention" - é muito mais comum em países cristãos do que no Oriente.

Em uma dissertação moral, que ele escreveu alguns anos atrás, em resposta a uma questão de prêmio, proposta pela Real Sociedade de Copenhagen, e que não ganhou o prêmio - (nosso filósofo não teve tanta sorte na Dinamarca quanto na Noruega), Schopenhauer exibe um grande trato de humor, enquanto ridiculariza o ideal moral e o "imperativo categórico" estabelecido por Kant. Não há dúvida de que o severo moralista da escola kantiana - se é que ele era alguma coisa mais que um ens rationis [ente racional], como o sábio homem dos estóicos - que nunca confiaria em um único impulso generoso, mas mergulharia em princípios abstratos de ação, enquanto o suplicante da caridade 
morreu de inanição diante de seus olhos - deve ter sido um personagem singularmente desagradável, e Kant, ao tentar elevar o domínio da razão, subestimava um elemento muito essencial na natureza humana.

O homem mau, de acordo com Schopenhauer, é aquele em quem a "vontade de viver" ganha tal predominância em sua forma individual, que ele ignora os direitos de suas semelhantes manifestações inteiramente, e os rouba e os mata, como parece se encontrar para própria vantagem dele. O homem justo, que é justo e nada mais, está mais alto na escala moral do que o homem mau, mas não alcançou a ideia de virtude de Schopenhauer. Ele até agora mostra uma simpatia com suas semelhantes criaturas que ele não interfere sobre seus direitos, mas não está disposto a fazer qualquer bem substancial. Ele é uma espécie de homem que paga seus impostos e taxas de igreja, mantém-se afastado do Tribunal de Solicitações e só é caridoso quando tem um equivalente na forma de um lugar honroso em uma lista de assinaturas.

O homem bom, como já vimos, é aquele cujo coração bate com simpatia por todas as criaturas em torno dele, praticamente, se não teoricamente, reconhecendo-as como manifestações da mesma grande vontade que ele próprio. Ele ama todos os seres vivos, desde o vizinho até uma rola-comum;e como as leis da natureza inanimada ainda são manifestações da única Vontade, ele pode consistentemente imitar o exemplo do homem da velha história, que considerava a sobrecarga de um carrinho-de-mão com uma perna como um exemplo de crueldade contra os animais. Mas não imagine que o ideal de Schopenhauer seja alcançado ainda. Acima do homem mau, o homem justo, o homem bom e toda a turba do vício e da virtude, surge ainda um personagem mais augusto, que precisa, contudo, de algumas observações preliminares para introduzi-lo.

Assim como pessoas ignorantes, que têm um conhecimento superficial de Berkeley, pensam que o bom bispo considerava o mundo inteiro como uma criação da fantasia, e que eles podem refutar seus discípulos dando-lhes uma enérgica (não metafórica) reprimenda, então sem dúvidas haverá pedantes que vão imaginar que, como Schopenhauer declarou que a vontade é a real essência do mundo, e que todo ser humano é uma manifestação dessa vontade, todo ser humano está em um estado de liberdade perfeita. Bem o reverso! Com respeito à vontade individual, Schopenhauer é um absoluto necessitário, sustentando que a ação de um certo motivo sobre um determinado caráter é tão segura de produzir um certo resultado, quanto uma operação de agente sobre o paciente na esfera da mecânica. O que pode ser um motivo para uma pessoa pode não ser um motivo para outra, pois os personagens podem ser diferentes; mas dado o caráter e o motivo, o resultado é infalível. A vontade absoluta, que estava além da jurisdição da causalidade, forçou-se no mundo dos fenômenos em uma forma individual, e deve levar as conseqüências, isto é, uma subjugação àquela lei de causa e efeito pela qual o todo o mundo dos fenômenos é governado, e é igualmente potente na descarga de uma pistola e no desempenho de uma 
ação virtuosa. O "caráter", que é a ideia do indivíduo humano, assim como a gravitação é uma das ideias da matéria, nasce com ele e não pode ser alterado. O conhecimento do indivíduo pode ser ampliado e, conseqüentemente, ele pode ser colocado em um caminho melhor, aprendendo que seus desejos naturais serão mais gratificados se ele obedecer às leis da sociedade, do que se ele se levantar contra eles; mas o personagem permanece o mesmo, embora a cupidez que teria feito um jogador ou um ladrão de estrada possa se tornar um elemento constituinte de um comerciante honesto. Assim, cada homem traz sua própria depravação no mundo com ele, e esta é a grande doutrina do pecado original, conforme estabelecido por Agostinho, exposta por Lutero e Calvino, e aplaudido por Schopenhauer, que, apesar de um livre-pensador, no sentido mais completo da palavra, é absolutamente deleitado com os pais e os reformadores, quando eles testemunham a degradação humana. O mundo dos fenômenos é uma desilusão - uma zombaria; e o fato de nascer em tal mundo é em si um mal. Assim pensou os apóstolos imediatos do cristianismo - assim pensou os anacoretas do deserto - assim pensou Calderón quando escreveu sua peça “A vida é um sonho”, que Schopenhauer cita com unção especial, -e, acima de tudo, assim dizem os professores do Hindustão. Se uma doutrina contrária é mantida na Europa, é o mero resultado do judaísmo, que com sua doutrina de uma primeira causa e seu sistema de recompensas temporais - isto é, seu otimismo - Schopenhauer considera com desprezo de um kantista consistente, e o ódio de um misantropo profundo. Cristianismo, ele pensa, é um resultado de hinduísmo, que se corrompeu na sua passagem pelo Palestina, e ele é irado excessivamente com essas sociedades missionárias que enviam de volta para a Índia a forma adulterada de uma doutrina que os nativos já possuem na maior pureza.

E agora podemos introduzir o ideal de Schopenhauer. O artista recebe grande parte de seu respeito, pois ele, sem considerar os motivos egoístas, contempla as idéias que formam o substrato do mundo dos fenômenos e os reproduz como o belo e o sublime. $\mathrm{O}$ homem bom, com sua enorme simpatia, é outro ser estimável; mas mais alto ainda é aquele que, convencido da ilusão do mundo, está decidido a destruí-lo, no que lhe diz respeito, extinguindo a vontade de viver. Suicídio não vai responder a esse propósito. O suicídio é uma antipatia por uma cadeia particular de circunstâncias, que se esforça por romper, mas não é uma alienação dos desejos individuais da vida em geral. Ascetismo, essa extinção gradual de todos os sentimentos que nos conectam com o mundo visível - a vida da anacoreta no deserto egípcio - do quietista da época de Luís XIV - do faquir indiano, que passa por anos de autotortura, - essa é a perfeição de Schopenhauer. O credo teológico particular sob o qual esses santos realizaram suas austeridades é uma questão de importância trivial - todos são semelhantes na única grande qualificação de santidade; eles recuaram do mundo visível e gradualmente extinguiram a "vontade de viver", até que a morte, comumente assim chamada, veio como a conclusão de seus desejos.

Neste ascetismo consiste a única liberdade possível da vontade. Enquanto atua no mundo dos fenômenos, a vontade torna-se emaranhada na lei da causalidade, mas agora 
recua de volta a uma região quando essa lei não pode mais operar e, por conseguinte, é livre. A liberdade da vontade é, em uma palavra, aniquilação, e esse é o maior benefício que pode ser desejado.

Quando Lord Byron trouxe seu herói, Childe Harold, para as fronteiras do mar, ele fechou seu poema; e agora que nós, auspício de Schopenhauer, trouxemos nossos leitores para as margens do nada absoluto, encerramos nosso artigo. Exceto no que diz respeito à recomendação do estilo do autor, pretendemos que seja um artigo de descrição - nada mais; e aqueles que interpretam qualquer de nossas observações na aceitação de tal sistema de ultra-pessimismo, mal-entenderam totalmente o nosso significado. Ao mesmo tempo, ficaremos muito surpresos se nosso breve esboço desse genial, excêntrico, audacioso e, digamos, terrível escritor, não tente alguns de nossos leitores a obter para si um conjunto de obras, cada página das quais abunda com sugestões novas e surpreendentes. Apenas desejamos que pudéssemos ver entre os filósofos da Alemanha moderna um escritor de igual poder, abrangência, engenho e erudição, de um lado mais em harmonia com nossos próprios sentimentos e convicções, do que aquele adotado por aquele sábio misantropo de Frankfurt..

\section{Referências}

BEISER, F. Weltschmerz: Pessimism in German Philosophy, 1860-1900. Oxford University Press, 2016.

DÖRPINGHAUS, A. Schopenhauers rhetorische Argumentation für den Pessimismus. Schopenhauer Jahrbuch, Würzburg, Bd. 80, 1999, pp. 63-85.

FREUD, S. Luto e Melancolia. Trad. de Marilene Carone, Cosac Naify, 2014.

JAMES, W. William James Writings, 1902-1910. Literary Classics of the United States, 1987.

MALTER, R. Il pessimismo: un concetto critico. In: La scuola di Schopenhauer: testi e contesti. Lecce: Pensa Multimedia, 2009, pp. 624-635.

NIETZSCHE, F. W. O nascimento da tragédia, ou Helenismo e Pessimismo. Trad. J. Guinsburg. - São Paulo, Companhia das Letras, 1992.

RATCLIFFE, M. Feelings of Being, Phenomenology, Psychiatry and the Sense of Reality. Oxford University Press, 2008.

RATCliffe, M. Experiences of Depression A Study in Phenomenology. Oxford University Press, 2009.

RATCLIFFE, M. What is it to lose hope? Phenomenology and the Cognitive Sciences Dec. 2013, Volume 12, Issue 4, pp 597-614. 
SCHOPENHAUER, A. O Mundo como Vontade e como Representação. Trad. Jair Barboza. Editora Unesp, 2005.

SIMMEL, G. Schopenhauer \& Nietzsche. Trad.César Benjamin. Contraponto Editora, 2005.

TOLSTOY. L. A Confession. Trans. Maude, A. Mineola, N.Y.: Dover Publications Inc, 2005.

VAN FRAASSEN, B. The Empirical Stance. Yale UNiversity Press, 2002. 